\title{
Dairy intake in relation to cardiovascular disease mortality and all-cause mortality: the Hoorn Study
}

\author{
Marieke A. van Aerde • Sabita S. Soedamah-Muthu • \\ Johanna M. Geleijnse $\cdot$ Marieke B. Snijder $\cdot$ Giel Nijpels • \\ Coen D. A. Stehouwer · Jacqueline M. Dekker
}

Received: 31 August 2011/Accepted: 18 April 2012/Published online: 5 May 2012

(C) The Author(s) 2012. This article is published with open access at Springerlink.com

\begin{abstract}
Purpose Existing data from prospective cohort studies on dairy consumption and cardiovascular diseases are inconsistent. Even though the association between total dairy and cardiovascular diseases has been studied before, little is known about the effect of different types of dairy products on cardiovascular diseases (CVD). The objective of this study was to examine the relationship between (type of) dairy intake and CVD mortality and all-cause mortality in a Dutch population.

Methods We examined the relationship between dairy intake and CVD mortality and all-cause mortality in 1956 participants of the Hoorn Study (aged 50-75 years), free of CVD at baseline. Hazard ratios with $95 \%$ CIs were obtained for CVD mortality and all-cause mortality per standard deviation (SD) of the mean increase in dairy intake, with adjustment for age, sex, BMI, smoking,
\end{abstract}

M. A. van Aerde · S. S. Soedamah-Muthu ( $₫)$ · J. M. Geleijnse Division of Human Nutrition, Wageningen University, PO Box 8129, 6700 EV Wageningen, The Netherlands

e-mail: sabita.soedamah-muthu@wur.nl

\section{B. Snijder}

Department of Public Health, Academic Medical Center,

University of Amsterdam, Amsterdam, The Netherlands

G. Nijpels · J. M. Dekker

EMGO Institute for Health and Care Research, VU University

Medical Center, Amsterdam, The Netherlands

C. D. A. Stehouwer

Department of Internal Medicine, Academic Hospital

Maastricht, Maastricht, The Netherlands

C. D. A. Stehouwer

Cardiovascular Research Institute Maastricht, Maastricht

University Medical Center, Maastricht, The Netherlands education, total energy intake, alcohol consumption, physical activity, and dietary intakes.

Results During 12.4 years of follow-up, 403 participants died, of whom 116 had a fatal CVD event. Overall dairy intake was not associated with CVD mortality or all-cause mortality. Each SD increase in high-fat dairy intake was associated with a $32 \%$ higher risk of CVD mortality (95\% CI; 7-61\%).

Conclusion In this prospective cohort study, the intake of high-fat dairy products was associated with an increased risk of CVD mortality.

Keywords Dairy - Cardiovascular diseases - Mortality . Prospective

\section{Introduction}

Cardiovascular diseases (CVD) are a major cause of death worldwide, claiming 17 million lives a year. Risk factors for CVD are smoking, overweight, hypertension, high plasma cholesterol levels, and diabetes mellitus [1]. Dietary recommendations for the prevention of CVD include reduced intake of saturated fat intake, for example by means of consuming low-fat dairy instead of whole-fat dairy [1].

Low-fat dairy foods are also one of the main components of the Dietary Approaches to Stop Hypertension (DASH) diet, which has been shown to lower blood pressure [2]. However, the beneficial effect could not be ascribed to the low-fat dairy products only, since the diet comprised many other components that are beneficial to health, such as fibers, fruits, and vegetables. Fermented dairy products may also have a beneficial effect on CVD, by reducing the cholesterol concentrations in the blood [3]. 
Among results of studies assessing the relationship between overall dairy intake and CVD, discrepancy exists. Some observational studies reported no association between dairy intake and CVD [4-8], while another study found an increased risk on developing CVD [9]. There are furthermore studies that found an inverse association between dairy intake and CVD [10-12]. There is growing evidence for a beneficial effect of dairy consumption on blood pressure [9, 13-15].

Despite the abundance of information, it is difficult to draw conclusions from the different studies. Dairy comprises many products, such as milk, cheese, yoghurt, and desserts. It is currently unclear how these specific dairy products like highfat dairy, low-fat dairy, cheese, or fermented dairy are associated with CVD. This is also supported by review articles and meta-analysis papers [16-21]. Some state that there is no clear evidence that higher dairy food consumption is consistently associated with a higher risk of CVD [17-19]. Others conclude that there is fairly convincing evidence that milk and dairy consumption is associated with an increase in survival in Western communities [20].

Gibson et al. [18] conclude that the studies available for examining the relationship between dairy food consumption and coronary heart disease (CHD) vary too much in design, quality, and dietary assessment methodology. Meta-analyses were mainly dominated by American studies, and often, no distinction was made between the different types of dairy.

Therefore, the purpose of the present study was to determine the relationship between (type of) dairy intake and CVD mortality and all-cause mortality in a Dutch cohort of men and women aged 50-75 years. Total dairy and the different subcategories (high-fat dairy, low-fat dairy, milk, milk and milk products, fermented dairy and cheese) were taken into account. Both CVD mortality and all-cause mortality were used as main outcomes. In the Netherlands, the consumption of dairy is naturally high and a large variety of dairy products is consumed. Only few studies have evaluated the relationship between dairy and dairy categories and the risk of CVD mortality.

\section{Subjects and methods}

\section{Study population}

The Hoorn Study is a Dutch cohort study of diabetes and diabetes complications among the general population, which began in 1989 . The study is conducted in 2,484 Caucasian men and women aged 50-75 years. The cohort and baseline measurements are described in detail elsewhere [22].

For this study, 477 subjects were excluded because they had CVD at baseline and 51 subjects were excluded because of missing information on dietary intake. Therefore, the analyses were performed in 1956 subjects (857 men and 1,099 women).

Written consent was obtained from all participants. The study was approved by the Ethics Committee of the VU Medical Center.

\section{Baseline measurements}

Weight and height were measured, and body mass index (BMI) was calculated as weight (kg) divided by height squared $\left(\mathrm{m}^{2}\right)$. Blood pressure was measured on the right arm with a random-zero sphygmomanometer (HawksleyGelman Ltd, Lancing, United Kingdom) while subjects were sitting.

Information on lifestyle factors was obtained by a selfadministered questionnaire, which was checked by a personal interview. Smoking status was categorized as current smoker, ex-smoker, or non-smoker. Physical activity was expressed in number of hours of physical activity per day. The activities included sports, bicycling, gardening, walking, doing odd jobs, and housekeeping. Alcohol intake was divided into four categories: non-drinker, $\leq 10,10-30$, and $\geq 30 \mathrm{~g} /$ day. There were three categories of educational level: low, medium, and high.

\section{Assessment of dairy consumption}

To assess dietary intakes of the participants, a 92-item validated semi-quantitative food-frequency questionnaire (FFQ) was used [23], which included the dairy consumption. The participants filled in the questionnaire at home, and the FFQs were checked in the research center for completeness.

Low-fat dairy was defined as milk products with a fat content $<2.0 / 100$ g or cheese products with a fat content $<20$ / $100 \mathrm{~g}$. High-fat dairy was defined as milk products with a fat content $>2.0 / 100$ g or cheese products with a fat content $>20$ / $100 \mathrm{~g}$. High-fat dairy was further divided into desserts (yoghurt, curds, custards, and ice-cream) and non-desserts (milk, cheese, porridge, and cream) [24]. The category "milk and milk products" included all kind of milk, yoghurt, coffee creamer, curd, pudding, porridge, and cream. The category "milk" included skimmed, semi-skimmed, and whole milk. The category "fermented dairy" included all fermented products, such as yoghurt, buttermilk, curds, and cheese products. The category "cheese" included all kinds of cheese, that is, soft cheese and hard cheese.

\section{Outcome measurements}

Information on mortality was obtained from the general practitioners and the local hospital. Causes of death were 
coded according to the International Classification of Diseases, Injuries, and Causes of Death, ninth revision (ICD-9). Fatal CVD was defined as ICD codes 390-459 (diseases of the circulatory system).

Data on fatal CVD were complete until 2005. The mean follow-up in years was 12.4 (24,312 person years).

\section{Statistical analysis}

Baseline characteristics are displayed for the total study population. Cox proportional hazard models were used to estimate hazard ratios (HRs with $95 \%$ CIs) for fatal CVD and all-cause mortality. Because of the limited cases for fatal CHD $(n=50)$ and stroke $(n=21)$, these endpoints were not analyzed separately.

The HRs were estimated per standard deviation (SD) of the mean of dairy product intake.

The basic model was not adjusted for any confounder (model 1). Model 2 included age (continuous) and sex. Subsequently, a multivariate analysis (model 3) was performed with adjustment for age, sex, BMI (continuous), smoking (3 categories), educational level (3 categories), total energy intake (continuous), and alcohol consumption (4 categories). Further adjustments (model 4) were then made for physical activity (continuous) and for intakes of meat, fish, bread, vegetables, fruit, coffee, and tea (continuous).

The statistical analyses were performed by using SAS software (version 9.2; SAS Institute, Cary, NC, USA).

\section{Results}

Baseline characteristics

Baseline characteristics of the study population are shown in Table 1. The mean age of this population was 61.6 years and $43.8 \%$ was male.

\section{Dairy consumption}

The median intake of total dairy products in this population was $425 \mathrm{~g} /$ day. Median intakes in the total population of high-fat dairy, low-fat dairy, fermented dairy, milk and milk products, milk, and cheese were 101, 250, 181, 394, 108, and 24 g/day, respectively (Fig. 1 for median intakes of dairy products and interquartile ranges).

The SDs of the mean intake (shown in Table 1) were $271 \mathrm{~g} /$ day for total dairy, $179 \mathrm{~g} /$ day for high-fat dairy, $260 \mathrm{~g} /$ day for low-fat dairy, $268 \mathrm{~g} /$ day for milk and milk products, $202 \mathrm{~g} / \mathrm{d}$ for milk, $182 \mathrm{~g} /$ day for fermented dairy, and $22 \mathrm{~g} /$ day for cheese.
Table 1 Mean $( \pm \mathrm{SD})$ baseline characteristics and dietary intakes of 1956 men and women from the Hoorn Study

\begin{tabular}{|c|c|}
\hline Characteristic & Value \\
\hline$N$ & 1,956 \\
\hline Age (year) & $61.1(7.2)$ \\
\hline Sex ( $\%$ male $)$ & 43.8 \\
\hline BMI $\left(\mathrm{kg} / \mathrm{m}^{2}\right)$ & $26.5(3.5)$ \\
\hline Physical activity (hour/day) & $4.4(2.7)$ \\
\hline \multicolumn{2}{|l|}{ Educational level } \\
\hline Low $(\%)$ & 80.2 \\
\hline Medium (\%) & 13.6 \\
\hline High $(\%)$ & 6.2 \\
\hline Current smoker (\%) & 31.5 \\
\hline Alcohol (g/day) & $9.0(12.2)$ \\
\hline Systolic BP (mmHg) & $135(20)$ \\
\hline Diastolic BP (mmHg) & $82(10)$ \\
\hline Serum total cholesterol $(\mathrm{mmol} / \mathrm{L})$ & $6.6(1.2)$ \\
\hline LDL-cholesterol (mmol/L) & $4.6(1.1)$ \\
\hline HDL-cholesterol (mmol/L) & $1.3(0.4)$ \\
\hline NDD $(\%)$ & 6.1 \\
\hline Known diabetes $(\%)$ & 2.8 \\
\hline Hypertension (\%) & 26.0 \\
\hline \multicolumn{2}{|l|}{ Dietary intakes } \\
\hline Energy intake (kcal/day) & $2,072(587)$ \\
\hline Total dairy $(\mathrm{g} / \text { day })^{\mathrm{a}}$ & $466.0(270.9)$ \\
\hline High-fat dairy $(\mathrm{g} / \text { day })^{\mathrm{b}}$ & $169.3(178.5)$ \\
\hline Low-fat dairy $(g / \text { day })^{c}$ & $295.3(260.4)$ \\
\hline Fermented dairy $(\mathrm{g} / \text { day })^{\mathrm{d}}$ & $218.2(182.1)$ \\
\hline Milk and milk products $(\mathrm{g} / \mathrm{day})^{\mathrm{e}}$ & $430.0(267.5)$ \\
\hline Milk $(\mathrm{g} / \text { dday })^{\mathrm{f}}$ & $166.3(202.4)$ \\
\hline Cheese $(\mathrm{g} / \text { day })^{\mathrm{g}}$ & $30.1(21.8)$ \\
\hline Meat (g/day) & $120.8(59.8)$ \\
\hline Fish (g/day) & $18.1(29.0)$ \\
\hline Bread (g/day) & $128.9(59.9)$ \\
\hline Vegetables (g/day) & $108.3(47.4)$ \\
\hline Fruit (g/day) & $229.5(152.3)$ \\
\hline Fiber (g/day) & $27.2(7.8)$ \\
\hline Coffee (mL/day) & $531.5(290.0)$ \\
\hline Tea (mL/day) & $296.9(251.4)$ \\
\hline Total fat (g/day) & $95.4(33.2)$ \\
\hline Saturated fat (g/day) & $40.1(14.7)$ \\
\hline Total protein (g/day) & $75.1(21.2)$ \\
\hline Total calcium (mg/day) & $1,091(409)$ \\
\hline
\end{tabular}

$B P$ blood pressure, $N D D$ newly detected diabetes

${ }^{\text {a }}$ Includes all dairy products, except butter

${ }^{b}$ Defined as all milk products with a fat content $>2.0 / 100 \mathrm{~g}$ or cheese products with a fat content $>20 \mathrm{~g} / 100 \mathrm{~g}$

${ }^{\mathrm{c}}$ Defined as all milk products with a fat content $<2.0 / 100 \mathrm{~g}$ or cheese products with a fat content $<20 / 100 \mathrm{~g}$

d Includes all fermented products, such as yogurt, buttermilk, curds, and cheese products

e Includes all kinds of milk, yoghurt, coffee creamer, curd, pudding, porridge, and cream (both low-fat and high-fat)

${ }^{\mathrm{f}}$ Includes all milk: skimmed, semi-skimmed, and whole milk

$\mathrm{g}$ Includes soft cheese and hard cheese (both low-fat and high-fat) 
Fig. 1 Median intakes and interquartile ranges of dairy products in $\mathrm{g} / \mathrm{day} . I Q R$ interquartile range $(\mathrm{p} 25, \mathrm{p} 75)$

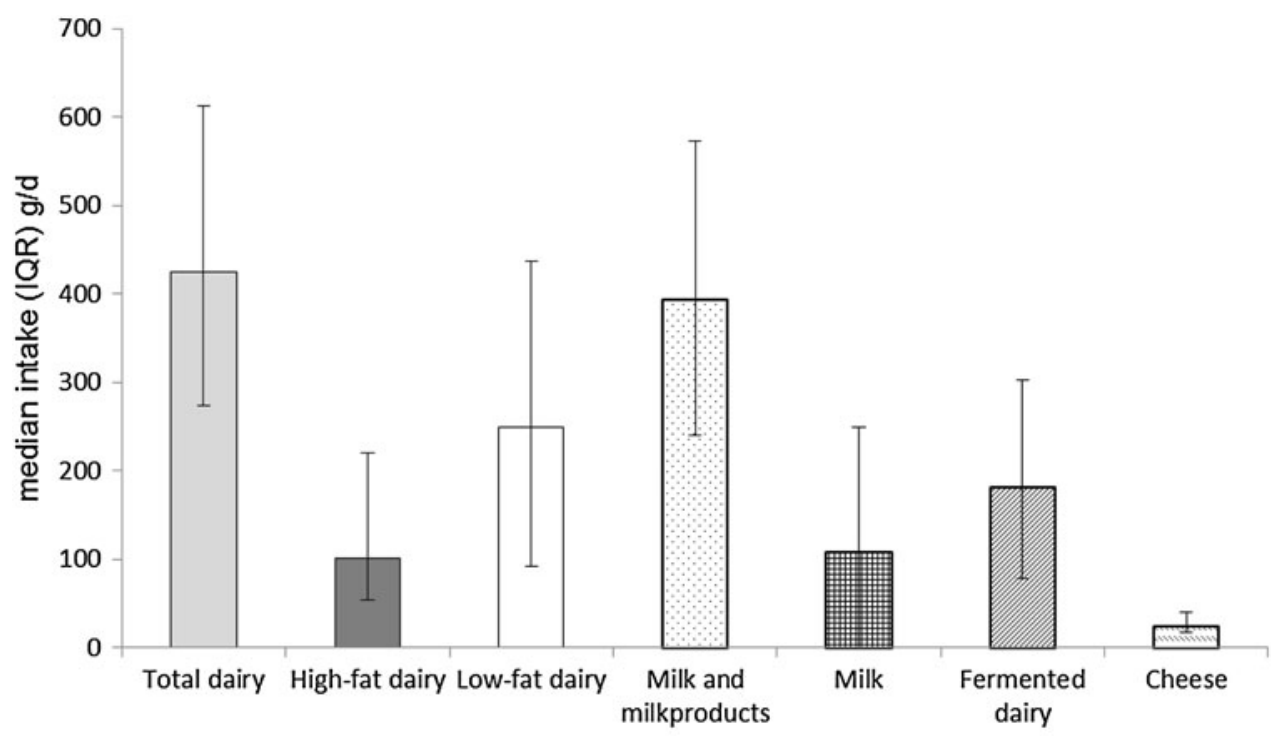

IQR: interquartile range (p25, p75)
Dairy intake and fatal CVD

Until January 2005, 403 subjects died, of whom 116 had a fatal CVD event.

No association was found between total dairy intake and CVD mortality (multivariate HR, 1.18; $95 \%$ CI, 0.96, 1.44). For high-fat dairy, however, each SD increase in intake was significantly associated with a $32 \%$ higher risk of CVD mortality (95\% CI, 7, $61 \%$ ) (Table 2). Additional adjustment for low-fat dairy increased the HR even further (HR, 1.38; $95 \%$ CI, 1.10, 1.72, data not shown in tables). Further adjustments for LDL-cholesterol, HDL-cholesterol, or hypertension only increased the HR further (data not shown in tables).

When physical activity was omitted from model 4 , since 255 participants had missing values on physical activity, the HR for each SD increase in high-fat dairy was 1.24 (95\% CI, 1.03, 1.49, data not shown in tables).

Additional adjustment for saturated fat intake slightly weakened the results (HR, 1.29; $95 \%$ CI, 1.04, 1.59, data not shown in tables), but this association remained statistically significant. Additional adjustments for total fat, protein, or calcium did not change the results (data not shown in tables).

Further division of high-fat dairy products into desserts (33\%) and non-desserts (66\%) demonstrated no statistically significant association between desserts and CVD mortality (multivariate HR per SD (77.8 g/day) increase, $1.10 ; 95 \% \mathrm{CI}, 0.90,1.35)$. On the other hand, consumption of non-desserts high-fat dairy was significantly associated with an increased risk of CVD mortality (HR per SD (145.5 g/day) increase, 1.28 ; $95 \% \mathrm{CI}, 1.06,1.55)$.
No statistically significant association was found between low-fat dairy and CVD mortality (Table 2). Furthermore, no statistically significant association was found between fermented dairy and CVD mortality and between cheese and CVD mortality.

Adjusting for energy according to the residual method of Walter Willett [25] gave identical results (data not shown).

Dairy intake and total mortality

There was no significant relationship between any of the dairy categories and total mortality. A significant inverse association was found between low-fat dairy and total mortality, fermented dairy and total mortality, and between cheese and total mortality in the crude model only. After further adjustments, the HRs did not remain statistically significant (Table 3).

\section{Discussion}

In this cohort study among 1956 Dutch men and women aged 50-75 years, a positive association was found between highfat dairy intake and the risk of CVD mortality.

Several observational studies have evaluated the association between dairy product intake and CVD outcomes $[4,8,9,11-14,24,26,27]$. The results of these studies were inconsistent, possibly because of the heterogeneity of the population and the differences in design and dietary assessment methodology used by the various studies, as well as the exposures and outcomes studied. Dairy intake is 
Table 2 Hazard ratios (HRs) and $95 \%$ CIs of fatal CVD per SD increase of dairy intake

\begin{tabular}{|c|c|c|c|c|}
\hline \multicolumn{5}{|l|}{ Fatal CVD $(n=116)^{*}$} \\
\hline & Model $1^{\mathrm{a}}$ & Model $2^{\mathrm{b}}$ & Model $3^{\mathrm{c}}$ & Model $4^{\mathrm{d}}$ \\
\hline \multirow[t]{2}{*}{ Total dairy $^{\mathrm{e}}$} & $1.07(0.90,1.28)$ & $1.04(0.88,1.23)$ & $1.06(0.88,1.29)$ & $1.18(0.96,1.44)$ \\
\hline & $P=0.46$ & $P=0.65$ & $P=0.54$ & $P=0.11$ \\
\hline \multirow[t]{2}{*}{ High-fat dairy ${ }^{\mathrm{f}}$} & $1.19(1.03,1.39)$ & $1.16(1.00,1.35)$ & $1.19(1.01,1.41)$ & $1.32(1.07,1.61)$ \\
\hline & $P=\mathbf{0 . 0 2}$ & $P=0.06$ & $P=\mathbf{0 . 0 4}$ & $P=\mathbf{0 . 0 0 9}$ \\
\hline \multirow[t]{2}{*}{ Low-fat dairy ${ }^{\mathrm{g}}$} & $0.93(0.77,1.12)$ & $0.93(0.78,1.12)$ & $0.94(0.78,1.14)$ & $1.01(0.83,1.23)$ \\
\hline & $P=0.42$ & $P=0.45$ & $P=0.52$ & $P=0.96$ \\
\hline \multirow[t]{2}{*}{ Milk and milk products ${ }^{\mathrm{h}}$} & $1.08(0.91,1.29)$ & $1.04(0.881,1.24)$ & $1.06(0.88,1.29)$ & $1.17(0.96,1.43)$ \\
\hline & $P=0.39$ & $P=0.63$ & $P=0.54$ & $P=0.13$ \\
\hline \multirow[t]{2}{*}{ Milk $^{\mathrm{i}}$} & $1.16(0.99,1.36)$ & $1.10(0.94,1.29)$ & $1.14(0.96,1.34)$ & $1.17(0.98,1.39)$ \\
\hline & $P=0.06$ & $P=0.23$ & $P=0.13$ & $P=0.09$ \\
\hline \multirow[t]{2}{*}{ Fermented dairy ${ }^{\mathrm{j}}$} & $0.85(0.69,1.04)$ & $0.91(0.75,1.11)$ & $0.90(0.73,1.11)$ & $1.01(0.80,1.27)$ \\
\hline & $P=0.11$ & $P=0.35$ & $P=0.32$ & $P=0.97$ \\
\hline \multirow[t]{2}{*}{ Cheese $^{\mathrm{k}}$} & $0.89(0.73,1.08)$ & $0.97(0.791,1.19)$ & $0.98(0.79,1.20)$ & $1.09(0.87,1.35)$ \\
\hline & $P=0.24$ & $P=0.77$ & $P=0.81$ & $P=0.46$ \\
\hline
\end{tabular}

The SDs were $271 \mathrm{~g} /$ day for total dairy, $179 \mathrm{~g} /$ day for high-fat dairy, $260 \mathrm{~g} /$ day for low-fat dairy, $268 \mathrm{~g} /$ day for milk and milk products, $202 \mathrm{~g} /$ day for milk, $182 \mathrm{~g} /$ day for fermented dairy, and $22 \mathrm{~g} /$ day for cheese

Bold values are statistically significant $(P<0.05)$

* Due to missings on confounding variables, the number of cases in model 3 is 108 (total: 1,848), and in model 4, this is 93 (total: 1,637)

${ }^{\text {a }}$ Unadjusted

b Adjusted for age and sex

c Adjusted for age, sex, BMI, smoking, educational level, total energy intake, alcohol consumption

d Adjusted as for model 1 with additional adjustment for physical activity and intake of meat, fish, bread, vegetables, fruit, coffee, and tea

e Includes all dairy products except butter

${ }^{\mathrm{f}}$ Defined as all milk products with a fat content $>2.0 / 100 \mathrm{~g}$ or cheese products with a fat content $>20 / 100 \mathrm{~g}$

$\mathrm{g}$ Defined as all milk products with a fat content $<2.0 / 100 \mathrm{~g}$ or cheese products with a fat content $<20 / 100 \mathrm{~g}$

h Includes all kinds of milk, yoghurt, coffee creamer, curd, cream, porridge, and pudding (both low-fat and high-fat)

i Includes all milk: skimmed, semi-skimmed, and whole milk

j Includes all fermented products, such as yogurt, buttermilk, curds, and cheese products

${ }^{\mathrm{k}}$ Includes soft cheese and hard cheese (both low-fat and high-fat)

a rather heterogeneous exposure, and little is known about specific types of dairy foods in relation to CVD.

Total dairy was not associated with CVD mortality and all-cause mortality in this study. A previous study within the Hoorn Study [24] showed that the consumption of highfat dairy was significantly inversely associated with cardiovascular risk factors such as BMI and lipid levels, which may seem inconsistent with our current results. However, the cross-sectional associations are likely to be disturbed by reversed causation [24], a phenomenon which is excluded in longitudinal studies. Our current results on mortality are in line with an earlier prospective analysis of the Hoorn Study, where no association was found between total dairy intake and changes in cardiovascular risk factors [27]. No distinction was made between different types of dairy in this study.

In the present study, high-fat dairy intake was associated with an increased risk of CVD mortality. Dairy foods, and especially high-fat dairy, contribute to the intake of saturated fat. Especially longer chain saturated fat has previously been associated with higher incidence of CHD [28]. Moreover, saturated fatty acids raise the LDL-cholesterol concentration in the blood, which is one of the main risk factors for CVD. A recent study of Goldbohm et al. [29] found that dairy fat intake was associated with slightly increased all-cause and ischemic heart disease mortality rates. Further evidence to support our positive results on high-fat dairy and CVD mortality came from ecological studies [30, 31] and controlled feeding studies finding associations on LDL-cholesterol [32, 33]. To explore whether the positive association between high-fat dairy and CVD mortality can be attributed to fat or more sugar containing products, we split our analyses by desserts. Increased risks for CVD were only found in the "nondesserts" category. This strengthened our suggestion that it is potentially the high amount of fat that causes this high 
Table 3 Hazard ratios (HRs) and $95 \%$ CIs of total mortality per SD increase of dairy intake

\begin{tabular}{|c|c|c|c|c|}
\hline \multicolumn{5}{|l|}{ Total mortality $(n=403)^{*}$} \\
\hline & Model $1^{\mathrm{a}}$ & Model $2^{\mathrm{b}}$ & Model $3^{c}$ & Model $4^{\mathrm{d}}$ \\
\hline \multirow[t]{2}{*}{ Total dairy ${ }^{\mathrm{e}}$} & $0.91(0.82,1.01)$ & $0.89(0.81,0.99)$ & $0.93(0.83,1.04)$ & $0.97(0.86,1.09)$ \\
\hline & $P=0.06$ & $P=\mathbf{0 . 0 3}$ & $P=0.23$ & $P=0.61$ \\
\hline \multirow[t]{2}{*}{ High-fat dairy ${ }^{\mathrm{f}}$} & $1.01(0.91,1.11)$ & $0.98(0.89,1.08)$ & $1.00(0.90,1.11)$ & $1.02(0.90,1.16)$ \\
\hline & $P=0.93$ & $P=0.71$ & $P=0.98$ & $P=0.72$ \\
\hline \multirow[t]{2}{*}{ Low-fat dairy ${ }^{\mathrm{g}}$} & $0.90(0.81,1.00)$ & $0.90(0.82,1.00)$ & $0.94(0.85,1.05)$ & $0.96(0.86,1.08)$ \\
\hline & $P=\mathbf{0 . 0 4}$ & $P=0.05$ & $P=0.27$ & $P=0.50$ \\
\hline \multirow[t]{2}{*}{ Milk and milk products ${ }^{\mathrm{h}}$} & $0.92(0.83,1.02)$ & $0.90(0.81,0.99)$ & $0.94(0.84,1.05)$ & $0.97(0.86,1.09)$ \\
\hline & $P=0.11$ & $P=\mathbf{0 . 0 4}$ & $P=0.25$ & $P=0.61$ \\
\hline \multirow[t]{2}{*}{$\operatorname{Milk}^{\mathrm{i}}$} & $0.96(0.87,1.06)$ & $0.92(0.83,1.01)$ & $0.96(0.86,1.07)$ & $0.96(0.86,1.08)$ \\
\hline & $P=0.39$ & $P=0.09$ & $P=0.43$ & $P=0.53$ \\
\hline \multirow[t]{2}{*}{ Fermented dairy ${ }^{\mathrm{j}}$} & $0.87(0.78,0.97)$ & $0.92(0.83,1.02)$ & $0.95(0.85,1.06)$ & $0.98(0.87,1.11)$ \\
\hline & $P=\mathbf{0 . 0 1}$ & $P=0.12$ & $P=0.33$ & $P=0.77$ \\
\hline \multirow[t]{2}{*}{ Cheese $^{\mathrm{k}}$} & $0.84(0.75,0.94)$ & $0.90(0.80,1.00)$ & $0.93(0.83,1.05)$ & $0.96(0.84,1.09)$ \\
\hline & $P=\mathbf{0 . 0 0 2}$ & $P=0.06$ & $P=0.26$ & $P=0.51$ \\
\hline
\end{tabular}

The SDs were $271 \mathrm{~g} /$ day for total dairy, $179 \mathrm{~g} /$ day for high-fat dairy, $260 \mathrm{~g} /$ day for low-fat dairy, $268 \mathrm{~g} /$ day for milk and milk products, $202 \mathrm{~g} /$ day for milk, $182 \mathrm{~g} /$ day for fermented dairy, and $22 \mathrm{~g} /$ day for cheese

Bold values are statistically significant $(P<0.05)$

* Due to missings on confounder variables, the number of cases in model 3 is 380 (total, 1,848), and in model 4 this is 332 (total, 1,637)

${ }^{a}$ Unadjusted

b Adjusted for age and sex

c Adjusted for age, sex, BMI, smoking, educational level, total energy intake, alcohol consumption

d Adjusted as for model 1 with additional adjustment for physical activity and intake of meat, fish, bread, vegetables, fruit, coffee, and tea

e Includes all dairy products except butter

${ }^{\mathrm{f}}$ Defined as all milk products with a fat content $>2.0 / 100 \mathrm{~g}$ or cheese products with a fat content $>20 / 100 \mathrm{~g}$

$\mathrm{g}$ Defined as all milk products with a fat content $<2.0 / 100 \mathrm{~g}$ or cheese products with a fat content $<20 / 100 \mathrm{~g}$

h Includes all kinds of milk, yoghurt, coffee creamer, curd, cream, porridge, and pudding (both low-fat and high-fat)

${ }^{i}$ Includes all milk: skimmed, semi-skimmed, and whole milk

j Includes all fermented products, such as yogurt, buttermilk, curds, and cheese products

${ }^{\mathrm{k}}$ Includes soft cheese and hard cheese (both low-fat and high-fat)

risk of CVD mortality. On the other hand, additional adjustment for saturated fat moderately reduced the association between high-fat dairy and CVD mortality, but remained statistically significant. It is therefore very well possible that besides saturated fat, there are other, unknown, components or mechanisms that could exert an effect on the risk of CVD mortality [34]. The consumption of high-fat dairy might for example reflect more unhealthy lifestyle or dietary pattern, which was not all measured. Residual confounding cannot be completely ruled out. Furthermore, when physical activity, the confounder with the largest number of missing values $(n=255)$, was removed from the final model, the hazard ratio became lower (HR, 1.24; $95 \%$ CI, 1.03, 1.49), but remained statistically significant. Caution is therefore needed with the conclusion that each SD increase in high-fat dairy intake would be associated with a $32 \%$ higher risk of CVD mortality.
There is growing evidence for a protective effect of lowfat dairy on blood pressure [13-15]. The mechanism by which especially low-fat dairy exerts a beneficial effect on blood pressure remains to be established. Vitamin K2, naturally present in fermented dairy products, has been recently suggested to decrease aortic calcification and CHD $[35,36]$.

In this study, fermented dairy and low-fat dairy were not statistically significantly associated with CVD mortality or all-cause mortality. Bernstein et al. [37] reported inverse associations between low-fat dairy and CHD only after 26 years of follow-up. It might be possible that the beneficial effect of fermented and low-fat dairy on CVD becomes visible after longer exposure and thus longer follow-up time.

Several strengths and limitations of our study need to be addressed. In the Netherlands, the intake of dairy products is naturally high, with a wide variety of dairy products that 
are consumed. To put this in perspective, in the most recent European Nutrition and Health report, the highest consumption of milk- and dairy-based products was reported in countries like Norway (522 g/day), Finland (437 g/day), the Netherlands ( $388 \mathrm{~g} / \mathrm{day})$, and United Kingdom (320 g/day), whereas intake was low in Austria ( $171 \mathrm{~g} /$ day), Poland (181 g/day), and the Czech Republic (186 g/day) [38]. In our data, the mean intake of dairy ( $466 \mathrm{~g} /$ day) was higher than in this report (mean dairy intake $266 \mathrm{~g} / \mathrm{capita} /$ day over 16 European countries) with a large variation, which enabled us to examine the relationship between dairy food consumption and CVD over a broad range of intake.

A possible limitation is the estimation of dairy intake used in the analysis, which was derived from a semiquantitative FFQ. The self-report of usual dietary intake could lead to misclassification. However, the FFQ was validated by comparison with a modified dietary history. Pearson correlation coefficients for estimates from the questionnaire and dietary history were on average 0.71 (range, 0.65-0.78) for macronutrients and 0.66 (range, 0.36-0.81) for vitamins and minerals [23]. Although the FFQ was not validated for dairy intake, high correlations were found for protein and calcium (0.69 and 0.75, respectively). Moreover, in the Netherlands, dairy is consumed on typical moments during the day, often during breakfast and/or lunch and after a hot meal, making it easier for the participants to recall the usual dairy intake.

A limitation of our study is that only dairy consumption at baseline was investigated, and not during follow-up. Participants may have changed their dietary pattern during the study. Although it cannot be assumed, 50- to 75-yearold adults may be less likely to change nutritional habits.

Another limitation is that we had a limited number of CVD and all-cause mortality cases. Therefore, we could not carry out analyses for dairy consumption by tertiles and presented continuous analyses per SD. Furthermore, no information on CVD morbidity was available. The participants had to give permission to access their hospital records, which only a small number of people did. It was therefore only possible to assess the relationship with mortality, and not with morbidity.

At last, a remark should be made about the age of the population. This study population was somewhat older than other cohorts, with an age between 50 and 75 years at baseline. Caution is needed with generalizing these results to a younger population.

In this Dutch prospective cohort study, the intake of high-fat dairy products was associated with an increased risk of CVD mortality.

Based on the results of this study, it can indeed be recommended to rather consume low-fat dairy instead of high-fat dairy in order to reduce the risk of CVD. However, to draw valuable conclusions, more research is needed in larger prospective studies with sufficient cases of stroke and CHD.

Acknowledgments The Hoorn Study has been made possible by the Vrije Universiteit Amsterdam and the VU University Medical Center, and by grants from the Dutch Diabetes Research Foundation, the Dutch Organization for Scientific Research, the Netherlands Heart Foundation, and the Health Research and Development Council of the Netherlands.

Conflict of interest Sabita S. Soedamah-Muthu and Johanna M. Geleijnse obtained an unrestricted grant from the Dutch Dairy Association (NZO) to carry out meta-analyses on the association between dairy products and CVD. Role of the sponsor: The sponsors were not involved in the conduct of the study or writing of the manuscript. There are no conflicts of interest reported by the other coauthors.

Open Access This article is distributed under the terms of the Creative Commons Attribution License which permits any use, distribution, and reproduction in any medium, provided the original author(s) and the source are credited.

\section{References}

1. World Health Organisation (2011) http://www.who.int/mediacentre/ factsheets/fs $317 /$ en/index.html

2. Appel LJ, Moore TJ, Obarzanek E, Vollmer WM, Svetkey LP, Sacks FM, Bray GA, Vogt TM, Cutler JA, Windhauser MM, Lin PH, Karanja N (1997) A clinical trial of the effects of dietary patterns on blood pressure. DASH Collaborative Research Group. N Engl J Med 336(16):1117-1124

3. St-Onge MP, Farnworth ER, Jones PJ (2000) Consumption of fermented and nonfermented dairy products: effects on cholesterol concentrations and metabolism. Am J Clin Nutr 71(3): 674-681

4. Elwood PC, Pickering JE, Fehily AM, Hughes J, Ness AR (2004) Milk drinking, ischaemic heart disease and ischaemic stroke I. Evidence from the Caerphilly cohort. Eur J Clin Nutr 58(5): 711-717

5. Shaper AG, Wannamethee G, Walker M (1991) Milk, butter, and heart disease. BMJ 302(6779):785-786

6. Van der Vijver LP, van der Waal MA, Weterings KG, Dekker JM, Schouten EG, Kok FJ (1992) Calcium intake and 28-year cardiovascular and coronary heart disease mortality in Dutch civil servants. Int J Epidemiol 21(1):36-39

7. Al-Delaimy WK, Rimm E, Willett WC, Stampfer MJ, Hu FB (2003) A prospective study of calcium intake from diet and supplements and risk of ischemic heart disease among men. Am J Clin Nutr 77(4):814-818

8. Houston DK, Driver KE, Bush AJ, Kritchevsky SB (2008) The association between cheese consumption and cardiovascular risk factors among adults. J Hum Nutr Diet 21(2):129-140

9. Larsson SC, Mannisto S, Virtanen MJ, Kontto J, Albanes D, Virtamo J (2009) Dairy foods and risk of stroke. Epidemiology 20(3):355-360

10. Umesawa M, Iso H, Date C, Yamamoto A, Toyoshima H, Watanabe Y, Kikuchi S, Koizumi A, Kondo T, Inaba Y, Tanabe N, Tamakoshi A (2006) Dietary intake of calcium in relation to mortality from cardiovascular disease: the JACC Study. Stroke $37(1): 20-26$ 
11. Bostick RM, Kushi LH, Wu Y, Meyer KA, Sellers TA, Folsom AR (1999) Relation of calcium, vitamin D, and dairy food intake to ischemic heart disease mortality among postmenopausal women. Am J Epidemiol 149(2):151-161

12. Ness AR, Smith GD, Hart C (2001) Milk, coronary heart disease and mortality. J Epidemiol Community Health 55(6):379-382

13. Wang L, Manson JE, Buring JE, Lee IM, Sesso HD (2008) Dietary intake of dairy products, calcium, and vitamin D and the risk of hypertension in middle-aged and older women. Hypertension 51(4): 1073-1079

14. Alonso A, Beunza JJ, Delgado-Rodriguez M, Martinez JA, Martinez-Gonzalez MA (2005) Low-fat dairy consumption and reduced risk of hypertension: the Seguimiento Universidad de Navarra (SUN) cohort. Am J Clin Nutr 82(5):972-979

15. Engberink MF, Hendriksen MA, Schouten EG, van Rooij FJ, Hofman A, Witteman JC, Geleijnse JM (2009) Inverse association between dairy intake and hypertension: the Rotterdam Study. Am J Clin Nutr 89(6):1877-1883

16. Tholstrup T (2006) Dairy products and cardiovascular disease. Curr Opin Lipidol 17(1):1-10

17. German JB, Gibson RA, Krauss RM, Nestel P, Lamarche B, van Staveren WA, Steijns JM, de Groot LC, Lock AL, Destaillats F (2009) A reappraisal of the impact of dairy foods and milk fat on cardiovascular disease risk. Eur J Nutr 48(4):191-203

18. Gibson RA, Makrides M, Smithers LG, Voevodin M, Sinclair AJ (2009) The effect of dairy foods on CHD: a systematic review of prospective cohort studies. Br J Nutr 102(9):1267-1275

19. Elwood PC, Pickering JE, Hughes J, Fehily AM, Ness AR (2004) Milk drinking, ischaemic heart disease and ischaemic stroke II. Evidence from cohort studies. Eur J Clin Nutr 58(5):718-724

20. Elwood PC, Givens DI, Beswick AD, Fehily AM, Pickering JE, Gallacher J (2008) The survival advantage of milk and dairy consumption: an overview of evidence from cohort studies of vascular diseases, diabetes and cancer. J Am Coll Nutr 27(6): 723S-734S

21. Soedamah-Muthu SS, Ding EL, Al-Delaimy WK, Hu FB, Engberink MF, Willett WC, Geleijnse JM (2011) Milk and dairy consumption and incidence of cardiovascular diseases and allcause mortality: dose-response meta-analysis of prospective cohort studies. Am J Clin Nutr 93(1):158-171

22. Mooy JM, Grootenhuis PA, de Vries H, Valkenburg HA, Bouter LM, Kostense PJ, Heine RJ (1995) Prevalence and determinants of glucose intolerance in a Dutch Caucasian population: the Hoorn Study. Diabetes Care 18(9):1270-1273

23. Grootenhuis PA, Westenbrink S, Sie CMTL, De Neeling JND, Kok FJ, Bouter LM (1995) A semiquantitative food frequency questionnaire for use in epidemiologic research among the elderly: validation by comparison with dietary history. J Clin Epidemiol 48(7):859-868

24. Snijder MB, van der Heijden AA, van Dam RM, Stehouwer CD, Hiddink GJ, Nijpels G, Heine RJ, Bouter LM, Dekker JM (2007)
Is higher dairy consumption associated with lower body weight and fewer metabolic disturbances? The Hoorn Study. Am J Clin Nutr 85(4):989-995

25. Willett WC, Howe GR, Kushi LH (1997) Adjustment for total energy intake in epidemiologic studies. Am J Clin Nutr 65(4 Suppl):1220S-1228S; discussion 1229S-1231S

26. Engberink MF, Geleijnse JM, de Jong N, Smit HA, Kok FJ, Verschuren WM (2009) Dairy intake, blood pressure, and incident hypertension in a general Dutch population. J Nutr 139(3): 582-587

27. Snijder MB, van Dam RM, Stehouwer CD, Hiddink GJ, Heine RJ, Dekker JM (2008) A prospective study of dairy consumption in relation to changes in metabolic risk factors: the Hoorn Study. Obesity (Silver Spring) 16(3):706-709

28. Hu FB, Stampfer MJ, Manson JE, Ascherio A, Colditz GA, Speizer FE, Hennekens CH, Willett WC (1999) Dietary saturated fats and their food sources in relation to the risk of coronary heart disease in women. Am J Clin Nutr 70(6):1001-1008

29. Goldbohm RA, Chorus AM, Galindo Garre F, Schouten LJ, van den Brandt PA (2011) Dairy consumption and 10-year total and cardiovascular mortality: a prospective cohort study in the Netherlands. Am J Clin Nutr 93(3):615-627

30. Moss M, Freed D (2003) The cow and the coronary: epidemiology, biochemistry and immunology. Int J Cardiol 87(2-3): 203-216

31. Segall JJ (1977) Is milk a coronary health hazard? Br J Prev Soc Med 31(2):81-85

32. Rossouw JE, Burger EM, Van der Vyver P, Ferreira JJ (1981) The effect of skim milk, yoghurt, and full cream milk on human serum lipids. Am J Clin Nutr 34(3):351-356

33. Steinmetz KA, Childs MT, Stimson C, Kushi LH, McGovern PG, Potter JD, Yamanaka WK (1994) Effect of consumption of whole milk and skim milk on blood lipid profiles in healthy men. Am J Clin Nutr 59(3):612-618

34. Moss M (2002) Does milk cause coronary heart disease? J Nutr Environ Med 12(3):207-216

35. Geleijnse JM, Vermeer C, Grobbee DE, Schurgers LJ, Knapen MH, van der Meer IM, Hofman A, Witteman JC (2004) Dietary intake of menaquinone is associated with a reduced risk of coronary heart disease: the Rotterdam Study. J Nutr 134(11): 3100-3105

36. Beulens JW, Bots ML, Atsma F, Bartelink ML, Prokop M, Geleijnse JM, Witteman JC, Grobbee DE, van der Schouw YT (2009) High dietary menaquinone intake is associated with reduced coronary calcification. Atherosclerosis 203(2):489-493

37. Bernstein AM, Sun Q, Hu FB, Stampfer MJ, Manson JE, Willett WC (2010) Major dietary protein sources and risk of coronary heart disease in women. Circulation 122(9):876-883

38. European Nutrition and Health Report (2009) Forum of nutrition. In: Elmadfa I (ed) Vienna, vol 62. Karger, Switzerland 